\title{
O que faz bem para a voz: análise de informações veiculadas pela internet
}

\author{
What is good for the voice: analysis of information used by the internet \\ Lo que hace bien para la voz: análisis de información transmitida por internet
}

Recebido: 31/08/2021 | Revisado: 07/09/2021 | Aceito: 23/09/2021 | Publicado: 25/09/2021

\author{
Sara Giovana Simões Gibeli \\ ORCID: https://orcid.org/0000-0001-8910-9050 \\ Pontifícia Universidade Católica de São Paulo, Brasil \\ E-mail: fonosarasimoes@gmail.com \\ Léslie Piccolotto Ferreira \\ ORCID: https://orcid.org/0000-0002-3230-7248 \\ Pontifícia Universidade Católica de São Paulo, Brasil \\ E-mail: lesliepf@pucsp.br \\ Ana Carolina Fonseca Rangel \\ ORCID: https://orcid.org/0000-0003-0886-6442 \\ Pontifícia Universidade Católica de São Paulo, Brasil \\ E-mail: anacfrangel@gmail.com
}

\begin{abstract}
Resumo
Analisar a forma e conteúdo de informações sobre o que faz bem para a voz, veiculadas em dez sites mais acessados da Plataforma Google. Esta pesquisa de natureza descritiva prescindiu de encaminhamento para o Comitê de Ética da Universidade. A plataforma escolhida para a busca dos dados foi a Google, uma vez que se tornou a principal ferramenta de buscas da internet. No dia 15 de abril de 2021, a plataforma foi acessada e a frase "o que faz bem para a voz" foi inserida para busca de dados. Nesse momento foi feito o registro de aproximadamente 142.000.000 resultados, sendo selecionados os dez links da primeira página. Os achados foram apresentados de forma numérica e percentual. Indicam que os sites utilizam palavras de fácil entendimento (100\%), apontam para a importância da ingestão de maçã (90\%), e de líquidos (90\%) e alertam para evitar leites e derivados (30\%), e fazer uso de gritos e sussurros $(50 \%)$. Concluiu-se que esses sites retratam informações presentes na literatura. Contudo, aspectos relacionados a saúde geral deveriam ser destacados e relacionadas a produção da voz.
\end{abstract}

Palavras-chave: Voz; Hábitos; Internet; Promoção da saúde; Acesso à informação.

\begin{abstract}
Analyze the form and content of information about what is good for the voice, served on ten most accessed Google Platform sites. This descriptive research did not need to be referred to the University Ethics Committee. The platform chosen to search the data was Google, as it became the main internet search tool. On April 15, 2021, the Google platform was accessed the phrase "what is good for the voice" was inserted for data search. At that time, the registration of approximately 142,000,000 results was made, and the ten links of the first page were selected. The findings were presented in numerical form and percentage. The results indicate that the sites use words that are easy to understand (100\%), point to the importance of eating apple (90\%) and liquids (90\%) and warn against milk and derivatives $(30 \%)$, and do use of screams and whispers $(50 \%)$. It was concluded that these sites portray information present in the literature. However, aspects related to general health should be highlighted and related to voice production.
\end{abstract}

Keywords: Voice; Habits; Internet; Health promotion; Access to information.

\section{Resumen}

Analizar la forma y el contenido de información sobre lo que hace bien a la voz, que se transmite en diez sitios web más visitados de la Plataforma Google. Esta investigación de naturaleza descriptiva prescindió de remisión al Comité de Ética de la Universidad. La plataforma elegida para la búsqueda de los datos fue Google, ya que se convirtió en la principal herramienta de búsqueda de internet. El 15 de abril de 2021, la plataforma fue accedida y la frase que hace bien para la voz fue insertada para búsqueda de datos. En ese momento se hizo el registro de aproximadamente 142.000.000 resultados, siendo seleccionados los diez enlaces de la primera página. Los hallazgos fueron presentados en forma numérica y porcentual. Indican que los sitios utilizan palabras de fácil comprensión (100\%), señalan la importancia de la ingesta de manzana (90\%), y de líquidos (90\%) y advierten para evitar leches y derivados (30\%), y hacer uso de gritos y susurros (50\%). Se concluyó que estos sitios representan la información presente en la literatura. Sin embargo, deberían destacarse aspectos relacionados con la salud general y relacionados con la producción de la voz.

Palabras clave: Voz; Hábitos; Internet; Promoción de la salud; Acceso a la información. 


\section{Introdução}

A voz é uma função do sistema estomatognático que, aliada à fala, possibilita a comunicação. A qualidade vocal do indivíduo é única, assim como suas características corporais ou sua personalidade. O conceito de "voz normal” varia bastante, sendo considerada aquela voz que soa agradável ao ouvinte, com predomínio de sons harmônicos, que é produzida sem esforço e com características condizentes com o sexo, com a estrutura corporal e com a personalidade do falante (Junqueira \& Trezza, 2006). No que diz respeito ao aspecto biológico, denomina-se a voz como um som perceptivo decorrente da intensidade, sendo explicada pela inter-relação entre a pressão e a velocidade de ar expiratório, que influenciam diretamente o volume. (Silva et al., 2021).

Dentre os procedimentos realizados pelo fonoaudiólogo, cabe destacar que a atenção aos cuidados com a voz tem sido priorizada, como base para estabelecer a realização de ações que atendam a demanda e queixa do sujeito.

Nos primórdios da Fonoaudiologia esse trabalho era denominado Higiene Vocal. Essa era definida como um procedimento fonoaudiológico utilizado na prevenção de alterações vocais, e também presente na reabilitação vocal (tratamento) e no aperfeiçoamento vocal (estética) como um fator imprescindível para a manutenção de uma voz saudável e eficiente (Behlau \& Pontes, 2004).

As principais técnicas preventivas estavam incluídas nos procedimentos de Higiene Vocal, que consistia em algumas normas básicas que auxiliavam a preservar a voz e a prevenir o aparecimento de alterações e doenças, principalmente por pessoas que utilizam mais a voz. O termo Higiene Vocal era utilizado, porque na época havia uma corrente (Higienismo) que assim denominava os cuidados em geral com a saúde (Behlau \& Pontes, 2004).

O Higienismo desenvolveu-se em meio às tensões de jogos de interesses econômicos e produtivos, à dominação das classes hegemônicas e às diferenças culturais e de identidade dos vários segmentos sociais. Os modos característicos de apropriação da cultura e de sensibilidades, os quais refletem as maneiras de os homens compreenderem o mundo e de nele se posicionarem também estavam presentes nessa época (Penteado et al., 2005).

$\mathrm{O}$ conceito de higiene, nesse contexto, estava relacionado às questões de religiosidade, uma vez que as práticas nessa direção se valem das crenças e rituais de limpeza, de purificação e de valorização de condutas morais e hábitos de vida determinados, tendo em vista a preparação das pessoas para se apresentarem aos deuses (Penteado et al., 2005).

Nesse momento, frente a um distúrbio de voz, as questões eram apresentadas de forma proibitiva, na direção de culpabilizar o sujeito por seus hábitos inadequados. Era comum nas orientações, o fonoaudiólogo apresentar os hábitos saudáveis utilizando o "não" como impositivo e imperativo, ou seja "não fumar” "não ingerir bebidas alcoólicas”, " não usar sprays", entre outras, alegando que essas práticas comprometeriam a produção da voz (Vieira, 2012).

Com o decorrer do tempo, esses cuidados foram sendo vistos e denominados de Saúde Vocal. O ponto central não se resume à simples substituição do termo "higiene" por "saúde", mas sinaliza a necessária reflexão acerca das práticas educativas em saúde, uma vez que a opção por uma ou por outra denominação implica mudanças de referenciais, enfoques e concepções que fundamentam a ação em saúde e a práxis fonoaudiológica (Pinho, 1998).

Mais recentemente a Fonoaudiologia deu início ao uso do termo Bem-estar Vocal, e o foco foi conduzido para além dos consultórios, em ações voltadas para as questões de promoção de saúde. Antes de pensar na voz, hábitos de alimentação, de sono e de lazer tem que ser considerados (Dessie-Leite et al., 2011).

Alguns hábitos vocais presentes entre os denominados profissionais da voz, falada (professor, atendentes em serviços de telemarketing, atores entre outros) e cantada (em especial os cantores) podem ser incompatíveis com o que se preconiza como bem-estar vocal, chegando a danificar os tecidos laríngeos e produzir uma qualidade de voz alterada (Ferreira et al., 2012). 
Dentre alguns dos hábitos prejudiciais presentes nas intervenções denominadas higiene vocal, saúde vocal ou bemestar vocal, estão o fumar, ingerir bebida alcoólica, estar exposto a poluição, fazer uso de drogas ou determinados medicamentos, fazer uma alimentação inadequada (quanto ao que ingere ou em que momento realiza), fazer uso de vestuário que compromete o uso adequado da voz, além de hábitos do próprio comportamento vocal como pigarrear, tossir e gritar (Behlau et al., 2012).

A pesquisa de Souza (1998) levantou aspectos referentes aos cuidados com a voz, mencionados por fonoaudiólogos ou outros profissionais, presentes desde o início do século XX até o ano de 1998.

Segundo essa pesquisa, de forma resumida, nos primórdios os conselhos para a manutenção da voz, eram: nunca emitir um som sem ter os pulmões cheios de ar; respirar bem; nunca falar inspirando; nunca forçar a voz, principalmente, quando se está resfriado ou enfermo; não falar ao ar livre, no tempo frio; evitar o fumo, o álcool, as pastilhas cáusticas, u sar agasalhos no pescoço; nunca falar quando houver barulho ao redor para não forçar as cordas vocais (pregas vocais); ficar em silêncio entre uma conversa e outra, entre uma leitura em voz alta e outra consecutiva, e muito mais entre dois discursos, uma vez que as cordas vocais (pregas vocais) necessitam de repouso; parar imediatamente ao se sentir cansado; nunca atender a bis, ao final de um espetáculo (Souza \& Mello, 1998).

Percebe-se que a maioria desses cuidados se perpetua até os nossos dias, e alguns se modificaram por conta do desenvolvimento tecnológico que propiciou novas descobertas relacionadas ao melhor entendimento da Anatomia e Fisiologia Vocal.

Outra pesquisa também apresenta um levantamento realizado por meio de entrevistas com profissionais da voz que relataram ações curativas ou preventivas, que na opinião deles eram benéficas para a voz. Foram mencionadas diferentes substâncias para usar em gargarejo envolvendo líquidos mornos e quentes reconhecendo essas práticas como benéficas. Segundo a autora, as chances reais de melhora da qualidade vocal são estruturadas a partir da eficácia do procedimento e/ou a técnica de emprego e mudanças nos hábitos vocais. Esses, aliados à mudança na organização psíquica e proprioceptiva corporal e vocal obtida por meio de uma execução ritualística e do desejo de manter-se agente da própria saúde, podem se constituir num cuidado efetivo para o sujeito (Viola, 1997).

Ao analisar as Campanhas de Voz incentivadas pela Sociedade Brasileira de Fonoaudiologia (SBFa), na perspectiva da promoção de saúde e prevenção de doenças, Dornelas (2015) dividiu seu estudo em três: no primeiro retomou o percurso histórico da Campanha de Voz e apresentou o que atualmente é proposto; no segundo averiguou as reportagens televisionadas em 2013 sobre o Dia Mundial da Voz; e no terceiro identificou, nas Campanhas premiadas entre 2005 à 2013, os pressupostos envolvidos nas práticas de Educação em Saúde. Como resultado do primeiro estudo, o autor traz que a Campanha de Voz tem se tornado uma prática permanente, e deve ser considerada a importância das esferas públicas cada vez mais se apropriarem do tema e garantirem a execução dessas ações. No segundo estudo concluiu que todas as regiões do Brasil foram contempladas com reportagens e o fonoaudiólogo foi o profissional que tratou do tema na maioria das reportagens, embora o enfoque dado nas entrevistas não foi em sua totalidade de uma mesma natureza, sendo ora de promoção, ora de prevenção ao distúrbio de voz. Finalmente no terceiro estudo o autor observou que nas Campanhas de Voz, a distribuição de material impresso contendo informações a respeito dos cuidados com a voz é a ação mais usual. Concluiu que as Campanhas de Voz representam um marco na mobilização dos fonoaudiólogos que passam a ter o tema como objeto de uma ação que se pretende educativa, informando a população das questões que podem auxiliar ou comprometer a produção da voz (Dornelas et al., 2015).

Percebe-se assim uma preocupação por parte do fonoaudiólogo em marcar a questão dos cuidados com a voz, como um procedimento importante para qualquer tipo de intervenção que venha a desenvolver com sujeitos que o procuram com queixa vocal ou com a necessidade de aprimorar o desempenho vocal. 
Com o advento da internet, muitas das informações, que antes eram transmitidas apenas pelo terapeuta para seus pacientes, começaram a ser veiculadas. No entanto, frequentemente por se constituir apenas em repositório informal de dados, as informações nem sempre podem trazer conhecimentos adequados.

A internet permite que o cidadão, mesmo com pouca habilidade para manipular dispositivos eletrônicos e baixo poder aquisitivo para adquiri-los, acesse uma quantidade incomensurável de informações (Paolucci et al., 2016). Uma pesquisa realizada pela TIC Domicílio (2019) e lançada pelo Comitê Gestor de Internet no Brasil (CGI), indicou que a procura por informações e serviços de saúde está entre as principais atividades realizadas na internet, representando $47 \%$ dos internautas brasileiros Independente da renda, grau de instrução e região do País em que residam, tal interesse talvez esteja associado ao fato de a saúde ter se tornado nos últimos anos uma das principais preocupações da humanidade e se transformado em um "valor supremo".

Dessa forma, o objetivo deste artigo é analisar a forma e conteúdo de informações sobre o que faz bem para a voz, veiculadas em sites disponibilizados na Plataforma Google.

\section{Metodologia}

Esta pesquisa de natureza descritiva prescindiu de encaminhamento para o Comitê de Ética da Universidade, considerando que seu objetivo é analisar informações disponibilizadas na internet, ou seja, de domínio público.

A plataforma escolhida para a busca dos dados foi a Google, uma vez que se tornou a principal ferramenta de buscas da internet. Em pesquisa realizada na Agência de Publicidade (AMPER, 2021), somente no mês de janeiro foram registradas nessa plataforma 3,113 milhões de visitantes únicos, com duração de 10 minutos e 58 segundos por consulta de busca, totalizando 92,2 bilhões de visitas, feitas nos mais diversos lugares e dispositivos. Essa plataforma oferece serviços na web que vão desde ferramentas de pesquisa, domínio de e-mail e navegador, até publicidade on-line, aplicativos, redes sociais e sistemas operacionais.

No dia 15 de abril de 2021, tal plataforma foi acessada e a frase "o que faz bem para a voz" foi inserida para busca de dados. Nesse momento foi feito o registro de aproximadamente 142.000 .000 resultados.

Os links encontrados na primeira página do Google foram selecionados, uma vez que os dados da própria plataforma apontam que $75 \%$ dos usuários que fazem uma pesquisa não passam da primeira página, e que geralmente o primeiro link que aparece é o mais completo em informações (Sobreira, 2018). A análise dos links foi feita considerando a proposta sugerida por Bardin (2006), ou seja, após a leitura flutuante do material, com destaque nas informações repassadas através de cada um deles, foram definidas categorias mais objetivas, que permitiram a classificação dos registros.

Para analisar a forma e conteúdo dos sites encontrados, foram priorizados aqueles que traziam informações gráficas (dessa forma foram excluídos os vídeos) e na sequência foram selecionados os 10 primeiros (top 10), elencados segundo ordem dos mais acessados e ano de criação (Quadro 1). 
Quadro 1- Registro dos sites em ordem de mais acessados e ano de criação que veiculam informações sobre "o que faz bem para a voz" (Top10).

1) Água, maçã, mel, bebidas quentes, limão, gargarejo e soro ajudam a voz

Link:http://g1.globo.com/bemestar/noticia/2012/06/agua-maca-mel-bebidas-quentes-gargarejo-e-soro-ajudamvoz.html

Responsável pelas informações: fonoaudióloga e médico otorrinolaringologista

Ano de criação: 2012

2) 14 cuidados para manter a voz saudável

Link: https://www.minhavida.com.br/saude/galerias/13136-14-cuidados-para-manter-a-voz-saudavel

Responsável pelas informações: fonoaudióloga e médico otorrinolaringologista

Ano de criação: 2016

3) Melhores alimentos para a voz

Link: https://cuidai.com.br/alimentos-para-a-voz/

Responsável pelas informações: estagiária de jornalismo

Ano de criação: 2020

4) Solte a voz! Saiba como cuidar da sua saúde vocal através de uma boa alimentação

Link:https://www.conquistesuavida.com.br/noticia/solte-a-voz-saiba-como-cuidar-da-sua-saude-vocal-atraves-deuma-boa-alimentacao_a3453/1

Responsável pelas informações: nutricionista

Ano de criação: 2017

5) Como cuidar bem da voz durante o dia a dia

Link: https://medprev.online/blog/prevencao/como-cuidar-bem-da-voz/

Responsável pelas informações: não informado

Ano de criação: indisponível

6) 7 dicas para manter a sua voz saudável

Link:https://www.schoolofrock.com.br/recursos/canto/7-dicas-para-manter-a-sua-voz-saudvel

Responsável pelas informações: não informado

Ano de criação: indisponível

7) 6 alimentos bons para a voz! (Como cuidar da voz)

Link: https://auladecantohoje.com/alimentos-bons-para-voz/

Responsável pelas informações: não informado

Ano de criação: 2020

8) Afinal, maça faz bem para a voz?

Link: http://www.falarempublico.com.br/afinal-maca-faz-bem-para-a-voz/

Responsável pelas informações: não informado

Ano de criação: indisponível

9) 14 dicas para você manter a voz saudável

Link: https://interne.com.br/14-dicas-para-voce-manter-a-voz-saudavel/

Responsável pelas informações: fonoaudióloga e médico otorrinolaringologista

Ano de criação: 2019 
10) Conheça 10 e mitos e verdade sobre a saúde da voz

Link:https://www.folhadelondrina.com.br/folha-mais/conheca-10-mitos-e-verdade-sobre-a-saude-da-voz1004523.html

Responsável pelas informações: fonoaudióloga

Ano de criação: 2018

Fonte: Autores (2019).

Cada site foi analisado quanto a forma e conteúdo.

No que se refere a forma, foram considerados os seguintes critérios: se o texto continha pergunta e resposta; fotos ilustrativas; palavras que indicam negação (não, nunca, etc.); verbo no imperativo; e vocabulário de fácil entendimento.

Quanto ao conteúdo, foram registradas quatro categorias definidas depois da análise de todos os sites, a saber: referência a ingestão de alimentos, de bebidas, hábitos e problemas de saúde. Cada uma dessas foi dividida em subcategorias, determinadas segundo descrito no Quadro 2.

Quadro 2 - Descrição das categorias e subcategorias estabelecidas para análise dos sites que trazem informações sobre "o que faz bem para a voz" (Top10)

\begin{tabular}{|l|l|}
\hline Alimentos & Ingerir maçã \\
& Ingerir alimentos gordurosos \\
& Ingerir leites e derivados \\
Comer chocolate \\
& Ingerir condimentos \\
\hline Bebidas & Ingestão de líquidos \\
& Ingestão de chá \\
& Ingestão de refrigerantes \\
& Ingestão de bebida alcóolica \\
& Evitar ingestão de café \\
\hline Hábitos & Bocejar \\
& Articular bem as palavras \\
& Realizar inalação \\
& Realizar gargarejo com água morna e sal ou soro fisiológico \\
& Realizar aquecimento \\
& Estar atento a respiração \\
& Pigarrear \\
& Fumar \\
& Falar por muito tempo \\
& Gritar ou sussurrar \\
& Falar sob estresse \\
& Falar em lugar barulhento \\
& Falar com esforço \\
& Falar rápido ou sem pausas \\
Ambiente com ar-condicionado
\end{tabular}

Fonte: Autores (2019).

Ao final, os dados foram analisados considerando a descrição numérica e percentual dos achados.

\section{Resultados}

Dentre os 10 sites analisados (Top10), percebe-se, a partir dos dados explicitados que a criação do primeiro deles se deu em 2011, e que quatro estão sob a reponsabilidade de fonoaudiólogo. 
Quanto à forma é possível observar que todos utilizam palavras de simples entendimento, nove fazem uso de fotos ilustrativas, sete utilizam o verbo no imperativo, seis utilizam a forma negativa ao apresentar determinado elemento, e três utilizam texto tipo pergunta e resposta. (Gráfico I)

Gráfico 1 - Análise dos aspectos referentes a forma, presentes nos sites (Top10);

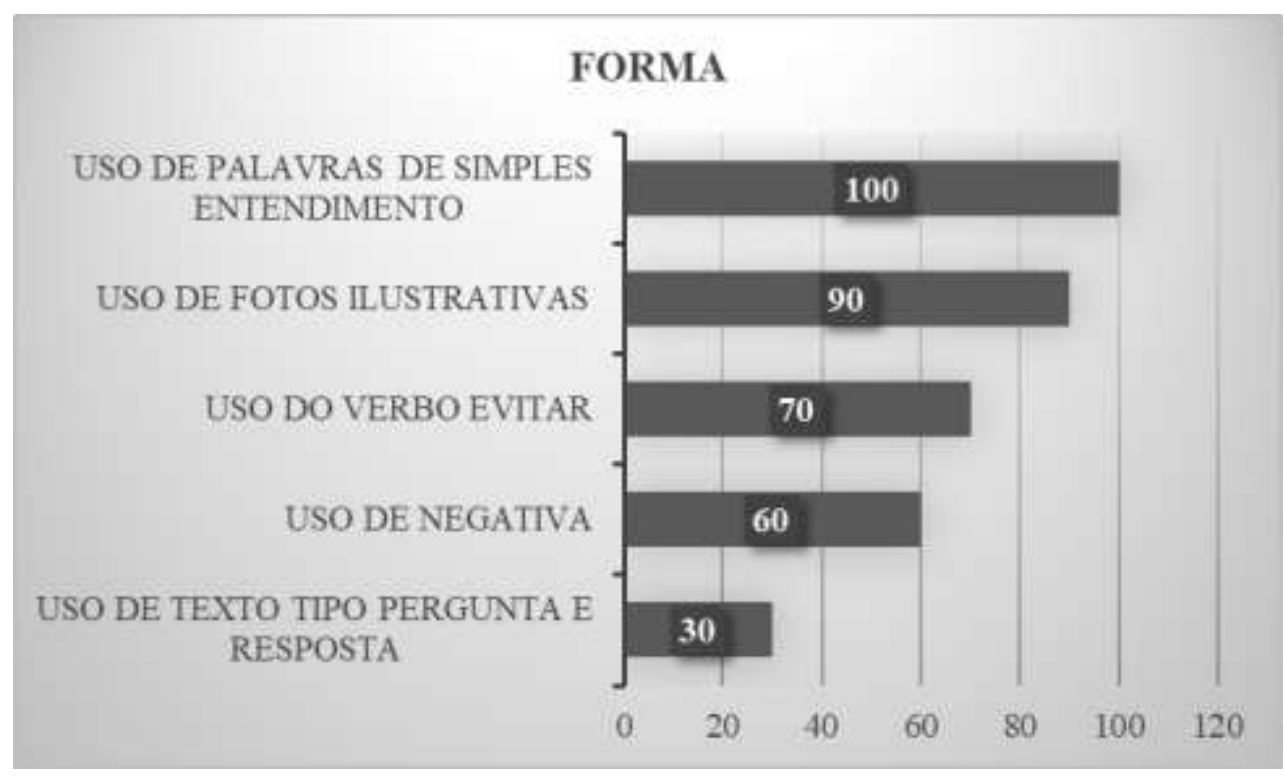

Fonte: Autores (2019).

Foi possível observar que quanto ao conteúdo presente nos sites (Gráfico 2), em relação a categoria referente a ingestão de alimentos, a maçã está presente e recomendada sua ingestão em nove dentre os dez sites analisados. Um deles explicita sua "ação adstringente, uma vez que é rica em pectina, substância que fornece ação adstringente e auxilia na "limpeza" da laringe e das pregas vocais, evitando o acúmulo de secreção (pigarro) nessa região". A ingestão de chocolate foi mencionada em quatro dos sites, alegando engrossar a saliva e atrapalhar a vibração das pregas vocais. Três deles falam sobre a questão de evitar alimentos gordurosos, assim como o uso de leites e derivados, alegando que o leite pode ocasionar um aumento na secreção e deixar a saliva grossa. Cinco dos sites mencionaram a ingestão de condimentos de forma negativa, afirmando que o exagero pode provocar irritação nas "cordas vocais".

Quanto a ingestão de bebidas, quase a maioria (nove) indica a água para a hidratação, afirmando ser essa a chave principal para cuidar das pregas vocais. Esses aconselham a ingestão de uma média de dois litros de água por dia, ou um copo de água a cada duas horas. Sete sites fazem referência de forma negativa a ingestão de bebida alcóolica alertando que a mesma irrita as vias respiratórias e altera a qualidade vocal, dando um efeito anestésico para as pregas vocais. Seis deles alertam para evitar o café, pois segundo um dos sites, desidrata as "cordas vocais", assim como o cigarro, e provoca um aumento da acidez no estômago, causando refluxo e ardor na hora de falar. Quatro sites fazem referência a ingestão de chá de forma positiva, orientando que ao consumi-lo de maneira moderada isso pode ajudar positivamente na voz.

Quanto aos hábitos de vida diária, esses em sua maioria foram apresentados com o verbo evitar no imperativo. Cinco sugerem evitar gritos e sussurros, uma vez que se essa atitude for frequente, a pessoa terá problemas, como hemorragias e edemas; cinco aconselham evitar o pigarro; sete a fumar e dois estar em ambiente com ar-condicionado. Um site alerta em relação a evitar falar sob estresse, falar em lugar barulhento, falar com esforço e falar rápido ou sem pausas.

Dentre as referências a hábitos positivos que melhoram a produção da voz, quatro apresentam a prática do bocejo, pois alonga as estruturas do trato vocal, dois indicam o gargarejo com água morna e sal, prestar atenção na respiração e quatro o 
aquecimento vocal. Dois dos sites sugerem articular bem as palavras e um estimular a prática de inalação para hidratação das pregas vocais.

Quanto aos problemas de saúde que podem interferir na produção da voz, três sites alertam para tirar do cardápio alimentos que causam azia e má-digestão. O motivo é o refluxo gástrico, que é ácido e pode irritar a garganta.

Gráfico 2 - Análise dos aspectos referentes ao conteúdo (alimentos, bebida, hábitos e problemas de saúde).

\begin{tabular}{|c|c|c|}
\hline \multirow{5}{*}{ ALIMENTOS } & EVITAR LEITE E DERIVADOS & $30 \%$ \\
\hline & EVITAR ALIMENTOS GORDUROSOS & $30 \%$ \\
\hline & EVITAR CHOCOLATE & $40 \%$ \\
\hline & EVITAR CONDIMENTOS & $50 \%$ \\
\hline & COMER MAÇÃ & $90 \%$ \\
\hline \multirow[t]{3}{*}{ BEBIDA } & EVITAR BEBIDA ALCÓOLICA & $70 \%$ \\
\hline & INGERIR ÁGUA & $90 \%$ \\
\hline & INGERIR CAFE + CHÁ & 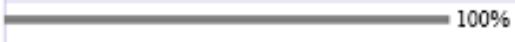 \\
\hline \multirow{12}{*}{ HÁBITOS } & REALIZAR INALACCÄO & $10 \%$ \\
\hline & ESTAR ATENTO A RESPIRAÇÃO & $20 \%$ \\
\hline & LREJO COM ÁGUA MORNA E SAL OU SORO FISIOLÓGICO & $30 \%$ \\
\hline & AQUECTMENTO VOCAL & $40 \%$ \\
\hline & EVITAR FALAR SOB ESTRESSE & $10 \%$ \\
\hline & EVITAR FALAR COM ESFORÇO & $10 \%$ \\
\hline & EVITAR FALAR EM LUGAR BARULHENTO & $10 \%$ \\
\hline & EVITAR FALAR RÁPIDO OU SEM PAUSAS & $10 \%$ \\
\hline & EVITAR AR CONDICIONADO & $20 \%$ \\
\hline & EVITAR GRITOS E SUSSUROS & $50 \%$ \\
\hline & EVITAR PIGARROS & $50 \%$ \\
\hline & EVITAR FUMAR & $70 \%$ \\
\hline \multirow[t]{2}{*}{ PROBLEMAS DE SAÚDE } & AZIA E MÁ DIGESTÃO & $30 \%$ \\
\hline & NDN (NADA DIGNO DE NOTA) & $=100 \%$ \\
\hline
\end{tabular}

Fonte: Autores (2019).

\section{Discussão}

De forma geral, assumir a perspectiva da promoção da saúde implica desvencilhar-se dos pressupostos higienistas e rever as concepções subjacentes às ações educativas em saúde. Da mesma forma, esse princípio deve ancorar as práticas voltadas a saúde vocal que poderão resultar em uma transformação significativa do cotidiano dos profissionais da voz em especial e de qualquer pessoa (Penteado et al., 2005).

Os princípios envolvidos na construção de ações de Educação em Saúde são os de promoção da saúde e de prevenção de doenças. Atualmente, a Educação em Saúde se caracteriza numa ação de promoção da saúde, com o intuito de tornar os indivíduos ativos e independentes no processo de autocuidado, estimulando a prática de hábitos saudáveis (Costa et al., 2004). Considerando a prevenção de distúrbios, os quais podem influenciar no processo saúde-doença, a realização destas ações possibilitam aos indivíduos uma melhor qualidade de vida. (Parente et al., 2020).

As ações de promoção da saúde são consideradas mais abrangentes e visam a abordagem dos processos relacionados a saúde-doença, envolvendo tanto o individual quanto o coletivo, principalmente na tomada de decisões. Para que essas ações ocorram, se faz necessário a constante circulação de informações acerca das políticas públicas de saúde (Konflanz et al.,2021). Em contrapartida, as ações voltadas para a prevenção possuem o objetivo da ausência de doença, ou seja, incentivando o indivíduo a realizar práticas necessárias a fim de evitar o adoecimento (Czeresnia, 2003). 
Cabe destacar que as informações disponibilizadas pelos sites analisados podem colaborar tanto na promoção, quanto na prevenção de distúrbios vocais, uma vez que proporciona mudanças no comportamento dos indivíduos. Porém, a forma como são apresentados nesses sites os benefícios e malefícios sobre o uso da voz, expõe a ideia de que caso o indivíduo não obedeça às recomendações, isso irá levá-lo ao adoecimento. Assim, somente informar o que faz bem e mal para a voz atualmente não é suficiente.

A falta de conhecimento de uma boa saúde vocal pode desencadear em uso excessivo e inadequado da voz, com consequentes problemas de atrito vocal, redução da capacidade vocal e desgaste do mecanismo vocal (Penteado et al., 2005). Vale ressaltar que a saúde vocal, ou o bem-estar vocal, envolve fatores como: a personalidade do indivíduo, contexto familiar, histórico de doenças prévias, influência do ambiente, além da percepção de sua própria voz. Dessa forma, é de suma importância a realização de ações com enfoque na promoção da saúde, pois essas permitam identificar precocemente aspectos que levam a distúrbios vocais e consequentemente a necessidade de intervenção fonoaudiológica (Silva et al., 2021).

Considerando que a internet pode ser uma boa ferramenta na divulgação de ações que podem colaborar para a promoção da saúde dos que nela procuram informações, por meio desta pesquisa foi possível analisar a forma e conteúdo veiculados em dez plataformas inseridas no Google sobre o que faz bem para a voz.

$\mathrm{Na}$ análise da forma dos conteúdos selecionados, pode se observar o uso de palavras de simples compreensão, acompanhado de fotos ilustrativas, que auxiliam no entendimento por parte das pessoas. Sabe-se que um site para ser avaliado como de boa qualidade requer além de um bom texto, o uso de imagens, que possam auxiliar na compreensão do que foi escrito.

Embora o acesso à internet não seja totalmente democrático no Brasil, não se pode negar o reconhecimento de vantagens que a rede proporciona para facilitar a comunicação e o acesso à informação nos mais diversos campos profissionais. Vantagens essas que são a disponibilidade e acesso a materiais, de diferentes formas (textos, vídeos, fotografias e outras fontes usadas na comunicação) e que não foram especialmente preparadas para fins exclusivamente pedagógicos (Amorim \& Lima, 2017).

Por outro lado, na análise realizada, ainda se registra o uso de palavras ou expressões como "evitar" e "não fazer X" indo de encontro as questões discutidas pela Fonoaudiologia, que alerta para ao fato de que ao proibir não se considera que um determinado hábito é colocado em prática não porque o sujeito quer, mas porque o contexto assim o determina. Frases do tipo "evite ingerir alimentos gordurosos", "evite pigarrear" identificam que o sujeito apresentava o hábito, mas que esse, para não mais ocorrer, depende de outros fatores e muitas vezes do auxílio de um profissional da saúde. A menção do "não" é mais evidente do que o "sim" e os hábitos positivos devem ser mais pontuados.

Em relação aos alimentos e bebidas, com a exceção de um site, fizeram referência a ingerir maçã, alegando ser um hábito saudável que auxilia na produção da voz com melhor qualidade e na limpeza da laringe, porém ao engolirmos o alimento, a epiglote é pressionada contra a laringe e o alimento possui apenas um caminho a seguir: o esôfago. A maçã de fato tem efeito de hidratação, é adstringente do trato vocal e a mastigação dela pode melhor a articulação das palavras, mas não pode estar em destaque que acabe por se sobrepor a outros fatores tão ou mais importantes.

Outro exemplo a ingestão de leite, apontado como devendo ser evitada, embora se saiba que em alguns casos, como entre pessoas que estão na chamada terceira idade, essa prática deve ser incentivada, por conta da presença de falta de cálcio no organismo (Passanha et al., 2011). Embora os aspectos apresentados nos sites de fato podem comprometer a produção da voz, a apresentação dos mesmos deve ser relativizada uma vez que "cada caso é um caso" e que um mesmo hábito pode ser benéfico para uma pessoa e prejudicial para outro.

Quanto a ingestão de líquidos, a maioria traz a questão da água e de fato a hidratação do corpo e consequentemente do sistema de fonação deve ser incentivado. Os resultados sobre ingerir líquidos, em específico, a água, vai na direção de que ela é 
um componente essencial de todos os tecidos corpóreos. Serve como solvente para minerais, vitaminas, aminoácidos, glicose e outras moléculas pequenas. Ela torna muitos solutos disponíveis para a função celular e é um meio necessário para todas as reações. É essencial para os processos fisiológicos de digestão, absorção e excreção e desempenha um papel-chave na estrutura e função do sistema circulatório e atua como um meio de transporte para os nutrientes e todas as substâncias corpóreas (Serafim et al., 2004). Por consequência, é um fator fundamental que auxilia na produção da voz com menor atrito e mais flexibilidade das pregas vocais, especialmente durante o uso intenso da voz, e pode ser considerado um hábito essencial a ser praticado pelos profissionais da voz (Aydos et al., 2000).

Cabe neste momento uma consideração: alguns sites descrevem a ingestão de alimentos ou de bebidas como positivas, uma vez que passarão pelas pregas vocais, o que, assim como ocorreu na explicação da ingestão da maçã, é uma informação incorreta, uma vez que apenas ar passa por elas. Caso algum alimento ou bebida por funcionamento inadequado do sistema ameaça adentrar a laringe, ou ele é expulso, numa ação posterior ao engasgo, ou pode ser causa de problemas pulmonares. Em relação a evitar bebida alcóolica, presente em sete dos sites analisados deve-se a irritação causada em todo trato vocal. Aparentemente, uma pequena dose de bebida alcóolica provoca a sensação de uma melhora da voz, em decorrência de uma inicial liberação do controle cortical, associada à anestesia da região da faringe (Pinho, 1998). Porém sabe-se que a ingestão de álcool é um problema de saúde pública, visto que é um hábito comum e milenar em muitas sociedades (Aydos et al., 2000). A ingestão em excesso de bebidas alcoólicas é considerada o quinto fator de risco mais importante para a ocorrência de mortes prematuras e incapacidades no mundo, dentre elas as doenças cardiovasculares, hepáticas, nutricionais e certos tipos de cânceres, além de causar dependência química e facilitar a ocorrência de violências e acidentes. $\mathrm{O}$ aumento do consumo abusivo no país pode ser justificado pela cultura reinante no Brasil que aceita socialmente o consumo de bebidas alcoólicas (Instituto Nacional do Câncer [INCA], 2019).

O fumo também é altamente prejudicial para o trato vocal, pois a fumaça quente do cigarro agride todo o sistema respiratório, trato vocal e principalmente as pregas vocais. Esta agressão pode levar à irritação do trato vocal, edema em pregas vocais e proporcionar o aparecimento de pigarro e tosse em decorrência do aumento da secreção. O cigarro afeta diretamente a movimentação ciliar da mucosa que envolve o músculo tireoaritenóideo, e as pregas vocais reagem a esse fenômeno defensivamente, com uma descarga intensa de muco (Pinho, 1998).

Segundo estudo feito pelo Instituto Brasileiro de Geografia e Estatística (IBGE, 2009) os cigarros são o principal produto consumido pelos usuários de derivados do tabaco. Os dados mais recentes do ano de 2019, a partir da Pesquisa Nacional de Saúde (PNS) apontaram o percentual total de brasileiros fumantes acima de 18 anos em 12,6\%, sendo 15,9 \% dos homens e $9,6 \%$ as mulheres, representando aproximadamente 22 milhões de pessoas. A pesquisa ainda indica que a idade média de experimentação de tabaco entre os jovens brasileiros é de 16 anos de idade, tanto para meninos quanto para meninas. Nacionalmente, a frequência de fumantes jovens do sexo masculino tende ser maior do que do sexo feminino (INCA, 2021).

A escolaridade é um fator que impacta na idade de começar a fumar: entre as pessoas sem instrução ou com menos de um ano de estudo, a proporção dos que começaram a fumar antes dos 15 anos de idade chega a 40,8\% (IBGE, 2009).

Cabe destacar que ingerir bebida alcoólica e fumar são dois hábitos de principal risco presentes em casos de câncer de laringe. O câncer de laringe ocorre predominantemente em homens acima de 40 anos e é um dos mais comuns entre os que atingem a região da cabeça e pescoço. Representa cerca de $25 \%$ dos tumores malignos que acometem essa área e $2 \%$ de todas as doenças malignas (INCA, 2019).

Em relação ao café, $60 \%$ dos sites alertam para evitar essa prática, apontando que eles desidratam as pregas vocais, assim como provocam um aumento da acidez no estômago, causando refluxo na hora de falar. Quanto ao chá, quatro sites apresentaram sua relação positiva, um deles explicitou na sequência a efusão com romã, dizendo que preparar um chá e fazer gargarejo são opções de "usar a romã como um aliado das cordas vocais", porém esse dado ainda não foi pesquisado de forma 
a assegurar benefícios. O que a literatura traz é sobre a questão do gengibre, pastilhas, sprays de própolis para tratar a voz, ou seja, esses produtos não tratam, apenas causam a sensação de anestesia, e podem contribuir, associado ao uso intensivo da voz, para ressecar a garganta (Vieira, 2012).

Destaque deve ser dado a questão do incentivo ao aquecimento vocal, presente em quatro dos sites.Essa ação é registrada na literatura e tem como proposta aumentar o fluxo sanguíneo, a oxigenação e a flexibilização dos tendões, ligamentos e músculos, possibilitando maior coaptação glótica, maior flexibilidade das pregas vocais para o devido alongamento e encurtamento durante as variações de frequência, qualidade vocal com maior componente harmônico, aumento do nível de pressão sonora (NPS) e melhora da projeção vocal e da articulação dos sons (Kyrillos \& Feijó, 2003).

Outros hábitos prejudiciais a produção da voz foram destacados nos sites pesquisados.

As pessoas são alertadas para não gritar, não falar sob estresse, evitar falar rápido, sem pausas ou com esforço, aspectos esses mencionados na literatura. Contudo, da maneira como foram apresentadas, mais uma vez transferem para o sujeito a tarefa de resolver o problema sem permitir uma análise mais detalhada sobre a questão. Condições do ambiente, como por exemplo presença de ruído, levam o sujeito a falar mais alto, mas ele, por si, não consegue reverter a situação. Ou mesmo momentos de estresse que na maioria das vezes não são gerados pelo sujeito, mas esse acaba por ser refém deles e vê sua voz refletir a situação. Resumindo, a questão é apresentada pelos sites, mas a solução do problema é banalizada, sem auxiliar o sujeito na busca de reverter o hábito.

Três dos sites trouxeram a questão da azia e má digestão. O motivo é o refluxo gástrico, que é ácido e pode irritar o trato vocal. Quando acontece a passagem do suco gástrico para o esôfago, em direção à boca, pode atingir a laringe e as pregas vocais, produzindo lesões por ser altamente irritativo. Várias substâncias podem acentuar o refluxo: alimentos muito gordurosos e condimentados, cafeína, leite e achocolatados, refrigerantes, álcool e frituras (Teixeira et al., 2011).

A atuação da Fonoaudiologia frente ao atendimento do cantor que sofre de refluxo baseia-se em orientações sobre os cuidados com a voz, e de forma paralela à atuação médica na remissão de alterações secundarias. Medidas preventivas tendem a orientações quanto a modificações de dieta - evitando alimentos condimentados, gordurosos, cítricos; cafeína e teína, bebidas alcoólicas e carbonatadas - e de hábitos de vida, como abster-se de fumo, evitar o uso da voz profissional logo após as refeições (Wolff, 2014).

O material disponibilizado na maioria dos sites analisados acaba por restringir a ações que devem ou não ser realizadas, numa perspectiva do mau uso ou abuso vocal, sem considerar outros aspectos que podem comprometer a produção da voz, como a questão dos fatores psicossociais.

Os sites deveriam incentivar mais as práticas que são boas para o melhor funcionamento do organismo, tais como, alimentação saudável. Somente dois sites possuem uma atenção voltada para essa questão. Cuidados com a alimentação incluem a necessidade de dosar os vários tipos de alimentos para garantir refeições equilibradas e nutritivas (Teixeira et al., 2011).

Deveriam destacar ainda a importância dos hábitos de sono, pois o ato de falar envolve um grande gasto de energia, e a fadiga vocal pode se instalar, e essa geralmente se reduz com um boa noite de sono (Wolff, 2014). Alguns fatores podem predispor às alterações do sono e devem ser controlados: atenção a ingestão de certos medicamentos, presença de refluxo gastroesofágico, obesidade, estresse, pouca atividade física e hábito de alimentar-se antes de dormir (Ribeiro et al., 2016).

Outra questão que deve ser abordada nos sites é a prática de atividades de lazer, uma vez que por falta de informação, nem todos sabem os benefícios que essa atividade traz para a qualidade de vida, entre eles o combate ao estresse, pois se acompanhadas de atividades físicas facilitam a circulação do sangue promovendo assim uma homeostase, ou seja, um equilíbrio no meio interno do corpo, colaborando na manutenção da saúde (Teixeira et al., 2011). 
Aspectos relacionados a saúde geral devem ser mais destacadas, uma vez que como disse Chico Buarque de Holanda: "o que é bom para o dono, é bom para a voz" (Buarque, 1991).

\section{Conclusão}

Os achados desta pesquisa revelam que os dez sites mais acessados, disponibilizados na plataforma Google e analisados retratam em sua maioria informações presentes na literatura. Contudo, a forma e o conteúdo como as informações são registradas podem culpabilizar o leitor que busca entender o seu problema de voz. Aspectos relacionados a saúde geral devem ser mais destacados, e relacionados a produção da voz. Considerando o crescente acesso nas plataformas digitais, recomenda-se outras análises em redes sociais como blogs, instagram e facebook, pois nos dias de hoje podem se constituir em locais onde é possível disseminar informações úteis para as pessoas, possibilitando assim melhora na sua qualidade de vida.

\section{Referências}

Amorim, E. M., \& Lima, S. C. (2017). Ensino de língua inglesa e letramento digital: uma análise de atividades em sites gratuitos de idiomas. Artefactum Revista de estudos em linguagem e tecnologia, 15(2), 1-10.

Aydos, R. B. S., Motta, L., \& Teixeira, S. B. (2000). Eficácia da hidratação na redução de queixas vocais de professores. Rev. Soc. Bras. Fonoaudiol, 14, 1015 .

Bardin L. (2006). Análise de Conteúdo. Edições 70.

Behlau, M. A., \& Pontes, P. A. (2009). Higiene Vocal: cuidando da voz. Revinter.

Behlau, M., Madazio, G., Rehder, M. I., Azevedo, R., \& Ferreira, A. E. Voz profissional: Aspectos Gerais da Atuação Fonoaudiológica. In: M. S., Behlau (Ed.). Voz: o livro do especialista. (2a ed.)..

Buarque, C. (1991). A voz do dono e o dono da voz. Almanaque.

Cgi.br (2021). Três em cada quatro brasileiros já utilizam a Internet, aponta pesquisa TIC Domicílios 2019. https://www.cgi.br/noticia/releases/tres-em-cadaquatro-brasileiros-ja-utilizam-a-internet-aponta-pesquisa-tic-domicilios-2019.

Costa, A. G., Monteiro, E. M. L. M., Vieira, N. F. C., \& Barroso, M. G. T. (2004). A dança como meio de conhecimento do corpo para promoção da saúde dos adolescentes. DST j. bras. Doenças sex. transm, 16 (3), 43-9.

Czeresnia, D. (2003). O conceito de saúde e a diferença entre prevenção e promoção. In: D., Czeresnia, C. M., \& Freitas (Eds.), Promoção da Saúde: conceitos, reflexões, tendências. (1 ed., pp.39-53). Rio de Janeiro: Fiocruz.

Dessie-Leite, A. P., Duprat, A. C., \& Busch, R. (2011). Comparação de hábitos de bem-estar vocal entre cantores líricos e populares. Rev. CEFAC, 13(1), 123131.https://doi.org/10.1590/S1516-18462010005000118.

Dornelas, R., Giannini, S. P., \& Ferreira, L. P. (2015). Dia Mundial da Voz em notícia: análise das reportagens sobre a Campanha da Voz no Brasil. CoDAS. 27(5), 492-7. https://doi.org/10.1590/2317-1782/20152014204.

Ferreira, L. P., Alves, I. A., Esteves, A. A., \& Biserra, M. P. (2012). Voz do professor: fatores predisponentes para o bem-estar vocal. Distúrb Comum, 24(3), $379-387$.

Instituto Brasileiro de Geografia e Estatística. (2009). 17,2\% dos brasileiros fumam; 52,1\% deles pensam em parar. https://censo2010.ibge.gov.br/noticiascenso.html?busca=1\&id=1\&idnoticia=1505\&t=17-2-brasileiros-fumam-52-1-deles-pensam-parar\&view=noticia.

Instituto Nacional do Câncer. (2021). Dados e números da prevalência do tabagismo. https://www.inca.gov.br/observatorio-da-politica-nacional-de-controledo-tabaco/dados-e-numeros-prevalencia-tabagismo.

Instituto Nacional do Câncer. (2019). Câncer de laringe.:https://www.inca.gov.br/tipos-de-cancer/cancer-de-laringe.

Junqueira P. A. S., \& Trezza, P. A. (2006). Princípios básicos da terapia vocal. In S. S. Costa; O. L. M. Cruz; \& J. A. O. Oliveira (Eds.), Otorrinolaringologia: princípios e práticas. (2 ed.) Porto Alegre: Artmed.

Konflanz, A. L., Rodrigues, S. A. Jr., Ferreti, F., \& Lutinski, J. A. (2021). Promoção da saúde realizada pela Estratégia de Saúde Bucal em municípios do sul do Brasil. Research, Society and Developmen, 10(10), 1-10. http://dx.doi.org/10.33448/rsd-v10i10.18814.

Kyrillos, L., Cotes, C., \& Feijó, D. (2003). Voz e corpo na TV: A fonoaudiologia a serviço da comunicação.: Globo.

Moura, E. C., \& Malta, D. C. (2011). Consumo de bebidas alcóolicas na população adulta brasileira: características sociodemográficas e tendência. Rev. bras. epidemiol, 14(1), 61-70. https://doi.org/10.1590/S1415-790X2011000500007. 
Research, Society and Development, v. 10, n. 12, e414101220065, 2021

(CC BY 4.0) | ISSN 2525-3409 | DOI: http://dx.doi.org/10.33448/rsd-v10i12.20065

Paolucci, R., Neto, A. P., \& Luiza, R. (2016). Avaliação da qualidade da informação em sites de tuberculose: análise de uma experiência participativa. Saúde debate, 41, 84-100. https://doi.org/10.1590/0103-11042017S08.

Passanha, A., Garcia, H. S., Certavo-Mancuso, A. M., Andrade, S. C., \& Vieira, V. L. (2011). Caracterização do consumo de leite em idosos. Rev. bras. crescimento desenvolv. hum., 21(2), 319-326.

Parente, F. S., Oliveira, R. C. M., Santos, L. C. M., Tsukimata, M. Y., Silva, J. M. R., Sacramento, R. C, Vasconcelos, L. A., Pereira, C. E. A., Sousa, J. S., \& Lopes, L. J. S. (2020). Health Education: a socio educational tool for health promotion for children in a public school in Belém do Pará, Brazil. Research, Society and Developmen, 9(7), 1-13. http://dx.doi.org/10.33448/rs-v9i7.3896.

Penteado, R. Z., Chun, R. Y., \& Silva, R. C. (2005). Do Higienismo às ações promotoras de saúde: a trajetória em saúde vocal. Distúrb Comum, $17(1), 9-17$.

Pinho, S. R. M. (1998). Fundamentos em Fonoaudiologia - Tratando os Distúrbios da Voz.:Guanabara Koogan.

Ribeiro, V. V., Frigo, L. F., Bastilha, G. R., \& Cielo, C. A. (2016). Aquecimento e desaquecimento vocais: revisão sistemática. Rev. CEFAC, 18(6), 14561465. https://doi.org/10.1590/1982-0216201618617215.

Serafim, A. L., Vieira, E. L., \& Lindemann, I. L. (2004). Importância da água no organismo humano. VIDYA- Revista eletrônica, 24, 147-150.

Sobreira, F. (2018). Primeira página do Google não é a mais importante. Disponível em: https://flammo.com.br/blog/primeira-pagina-do-google/.

Souza T., Mello, T. (1998). Um século de cuidados com a voz profissional falada: a contribuição da fonoaudiologia. Dissertação mestrado, Pontifícia Universidade Católica de São Paulo, São Paulo, SP, Brasil.

Silva, N. K. S. de., Bandeira, M. P. A., \& Sousa, K. Y. B. de. (2021). Perfil vocal dos professores de uma escola filantrópica da Cidade de Teresina. Research, Society and Developmen, 10(8), 1-13. http://dx.doi.org/10.33448/rsd-v9i7.3896.

Teixeira, M. A. B. Jr., Sferra, L. F. B., \& Bottcher, L. B. (2011). A importância do lazer para a qualidade de vida do trabalhador. Revista Portuguesa de Ciências do Desporto.

Vieira, V. P. (2012). Distúrbios da voz - "rouquidão”. Orientações baseadas em evidências para os pacientes. Diagn Tratamento, 17(3), 138-9.

Viola, I. C. (1997). Estudo descritivo das crenças populares no tratamento das alterações vocais em profissionais da voz. Dissertação de mestrado, Pontifícia Universidade Católica de São Paulo, São Pauto, SP, Brasil.

We are social e hootsuite. (2021). https://www.amper.ag/post/we-are-social-e-hootsuite-digital-2021-resumo-e-relat\%C3\%B3rio-completo.

Wolff, G. S. (2014). Relação entre voz e doença do refluxo em cantores: revisão de literatura. Monografia de graduação, Universidade Federal de Santa Catarina, Florianópolis. SC, Brasil. 